\title{
metabolites
}

ISSN 2218-1989

Review

www.mdpi.com/journal/metabolites/

\section{Role of Cereal Secondary Metabolites Involved in Mediating the Outcome of Plant-Pathogen Interactions}

\author{
Lauren A. Du Fall and Peter S. Solomon* \\ Research School of Biology, College of Medicine, Biology and Environment, The Australian National \\ University, ACT, 0200, Australia \\ * Author to whom correspondence should be addressed; E-Mail: peter.solomon@anu.edu.au.
}

Received: 4 November 2011; in revised form: 21 November 2011 / Accepted: 29 November 2011 /

Published: 15 December 2011

\begin{abstract}
Cereal crops such as wheat, rice and barley underpin the staple diet for human consumption globally. A multitude of threats to stable and secure yields of these crops exist including from losses caused by pathogens, particularly fungal. Plants have evolved complex mechanisms to resist pathogens including programmed cell death responses, the release of pathogenicity-related proteins and oxidative bursts. Another such mechanism is the synthesis and release of secondary metabolites toxic to potential pathogens. Several classes of these compounds have been identified and their anti-fungal properties demonstrated. However the lack of suitable analytical techniques has hampered the progress of identifying and exploiting more of these novel metabolites. In this review, we summarise the role of the secondary metabolites in cereal crop diseases and briefly touch on the analytical techniques that hold the key to unlocking their potential in reducing yield losses.
\end{abstract}

Keywords: secondary metabolite; plant defence; pathogen; cereal; metabolism; benzoxazinoid; isoprenoid; terpene; flavonoid; cyanogenic glycoside; saponin

\section{Introduction}

Eight major cereal crops including wheat, rice, barley, oat, rye, corn, sorghum and millet make up two-thirds of the worlds food supply [1]. Estimates list approximately 2.5 billion tonnes of cereals were produced in 2009, steadily growing from 800 million tonnes in the 1960's [2]. Biotic stresses, such as those caused by fungal pathogens, represent the greatest threat to global cereal production. For 
example, an epidemic of rice blast disease caused disastrous crop losses across China in the 1980's affecting up to $12 \%$ of the its rice acreage [3]. Fusarium head blight (scab; FHB) has historically been responsible for extensive crop losses throughout the world ranging from $15 \%-50 \%$ of wheat, barley and oat crops [4]. Rust fungus is also a significant pathogen of cereals causing losses of $0.73-1.73$ million tonnes in India and Pakistan during 1972 and 1973 [1]. These are but a handful of many such examples.

Taking into account the vast number of potential plant pathogens that exist, the actual amount of disease is relatively small. This is attributable to an intricate array of defence mechanisms plants have evolved over time as a necessity to survive their immobile nature. Typically, disease is avoided when a host plant recognises the presence of a pathogen. This recognition activates various plant defence responses including phytoalexin production, primary metabolite signalling, production of reactive oxygen species, protease and chitinase production, cross-linking of cell wall polymers, production of pathogenesis related (PR) proteins and the hypersensitive response, which leads to localised cell death [5]. Physical defence mechanisms are also crucial in pathogen attack namely solidifying of cell walls with lignin, polymerisation and crosslinking also to strengthen cell walls and the presence of cuticular waxes. For a review on plant defence responses see [6].

Plants synthesise a diverse range of secondary metabolites active in defence against a wide variety of pathogens [7]. These secondary metabolites offer a survival advantage to the plant during pathogen attack but are generally considered non-essential for basic plant metabolism (Dixon, 2001). These metabolites have various roles such as feeding deterrents, allelopathic compounds and antimicrobial agents [8] and are either constitutively produced (phytoanticipans) or pathogen/stress induced compounds (phytoalexins) [9,10].

In recent years, substantial advances have been made in discovering and characterising secondary metabolites from both plant and animal sources. Significant technological advancements in high throughput and mass spectrometry (MS) have evolved a new research discipline called metabolomics the study of small molecules in biological systems. A number of techniques are used for high throughput analysis of an extensive range of structurally and chemically diverse metabolites. Gas Chromatography-Mass Spectrometry (GC-MS) is utilised for analysis of polar metabolites following chemical derivatisation and volatiles using headspace analysis. Liquid Chromatography-Mass Spectrometry (LC-MS) is capable of analysing a range of polar and semi-polar compounds for which no chemical derivatisation is required. Nuclear Magnetic Resonance (NMR) Spectroscopy and Fourier Transform Infrared (FTIR) Spectroscopy are also utilised to structurally characterise small molecules however due to a combination of cost and complexity of the resulting data they are not as common as GC and LC-MS. These techniques enable identification and quantification of metabolites, which through carefully designed biological experiments, can be utilised to unravel the complex metabolite responses of plants to pathogens. An advantage of these metabolomics approaches over genomic and proteomic approaches is the ability to determine the exact metabolic state of the plant after pathogen infection.

This review will describe secondary metabolites involved in mediating the outcome of plantpathogen interactions in cereals. Secondary metabolites will be discussed in the context of chemical class rather than their roles as phytoanticipan or phytoalexins as a number of compounds fall into both these categories in different species. These secondary metabolites offer tremendous potential for plant breeding and metabolic engineering in agriculture to aid in controlling existing disease losses $[11,12]$. 


\section{Benzoxazinoids}

Benzoxazinoids (Bxs) are a class of secondary metabolites widely distributed in cereals discovered in the 1950's and since found to have a range of biological roles including alleopathy, resistance to insects and defence against pathogens [13-15]. Bxs are synthesised from the amino acid tryptophan in the shikimate pathway (Figure 1). They are present in maize; wheat, rye and certain wild barley species however have not been found in cultivated barley varieties, oat or rice [15,16]. These compounds are found in all parts of the plants but are present at higher levels in younger leaves [15]. Bxs are stored in an inactive glucoside form in plant vacuoles or plastids to avoid toxicity to the plant itself; they undergo enzymatic and chemical degradation upon tissue disruption to form the active benzoxazinoid $[16,17]$. The mechanism by which these compounds exert phytotoxic activity may be due to: their mutagenic effects on DNA, ability to react with amino acids and perhaps therefore disrupt proteins [18].

Figure 1. Simplified diagram illustrating the biosynthetic pathways of the discussed plant secondary metabolites involved in pathogen defence. Cyanogenic glucosides, flavonoids and benzoxazanoids are all synthesised from the aromatic amino acids derived from shikimate. Saponins and terpenoids are synthesised via the melavonate or non-melavonate pathway in plants, which occur in the cytoplasm and plastids of plants respectively.

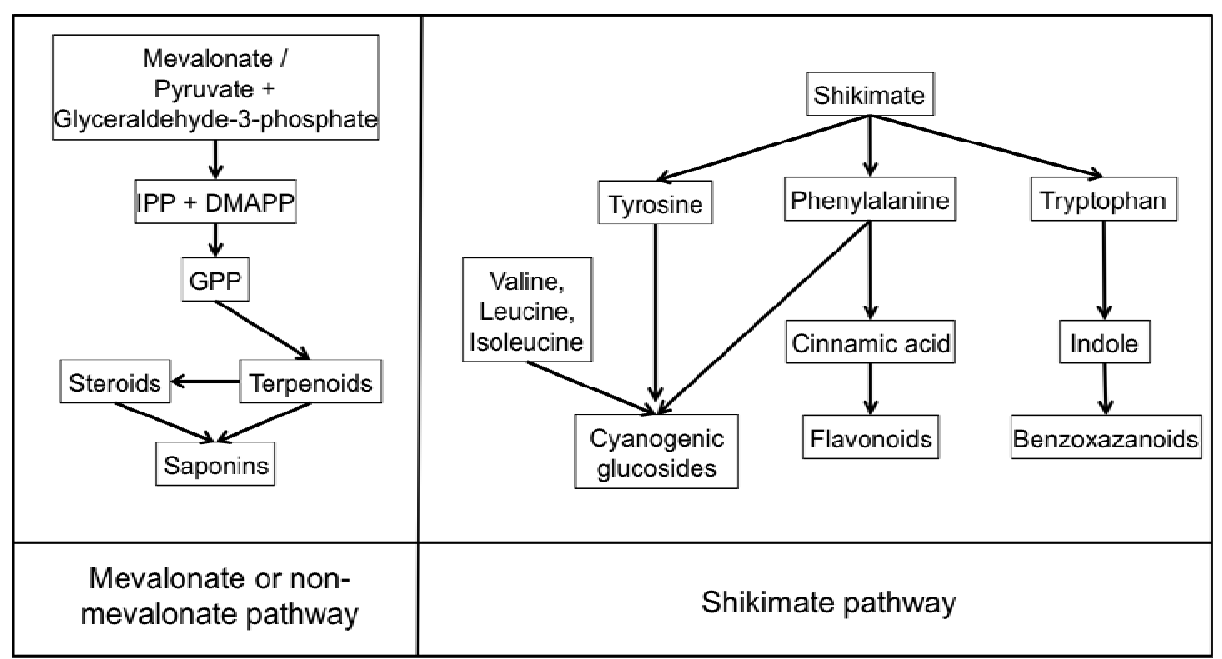

The most common Bx in rye and wild barley is 2,4-dihydroxy-2H-1,4-benzoxazin-3(4H)-one (DIBOA) and in maize and wheat is 2,4-dihydroxy-7-methoxy-2H-1,4-benzoxazin-3(4H)-one (DIMBOA) (Table 1). Bxs are also involved in plant defence against pathogenic fungi that cause very little tissue disruption [19] suggesting other methods of Bx-mediated resistance. Ahmad et al. [20], investigated the role of Bxs in resistance of maize to the necrotrophic fungus Setosphaeria turtica at stages prior to tissue disruption. They found that Bxs accumulate at the highest concentration in apoplastic leaf extracts and are critical for basal resistance against $S$. turtica. Bxs therefore have roles as defence metabolites as well as a defence regulatory signal in maize. Recently, a number of new Bx derivatives were identified using Ultra Performance LC-MS/MS [21]. The authors identified double hexose derivatised metabolites of the three Bxs DIBOA, HBOA (2-(2-hydroxy-1,4(2H)-benzoxazin-3(4H)-on)- $\beta$-D-glucopyranoside and DIMBOA in whole grain rye and wheat; however not in oat or barley. The location of the hexose moieties on the Bx structure, the presence of these compounds in other parts of the plant and the role of these double hexose derivatised Bxs in plant resistance to pathogens is yet to be ascertained. 
Table 1. Diagram illustrating the structures of a number of plant secondary metabolites belonging to the major classes of defence compounds discussed.

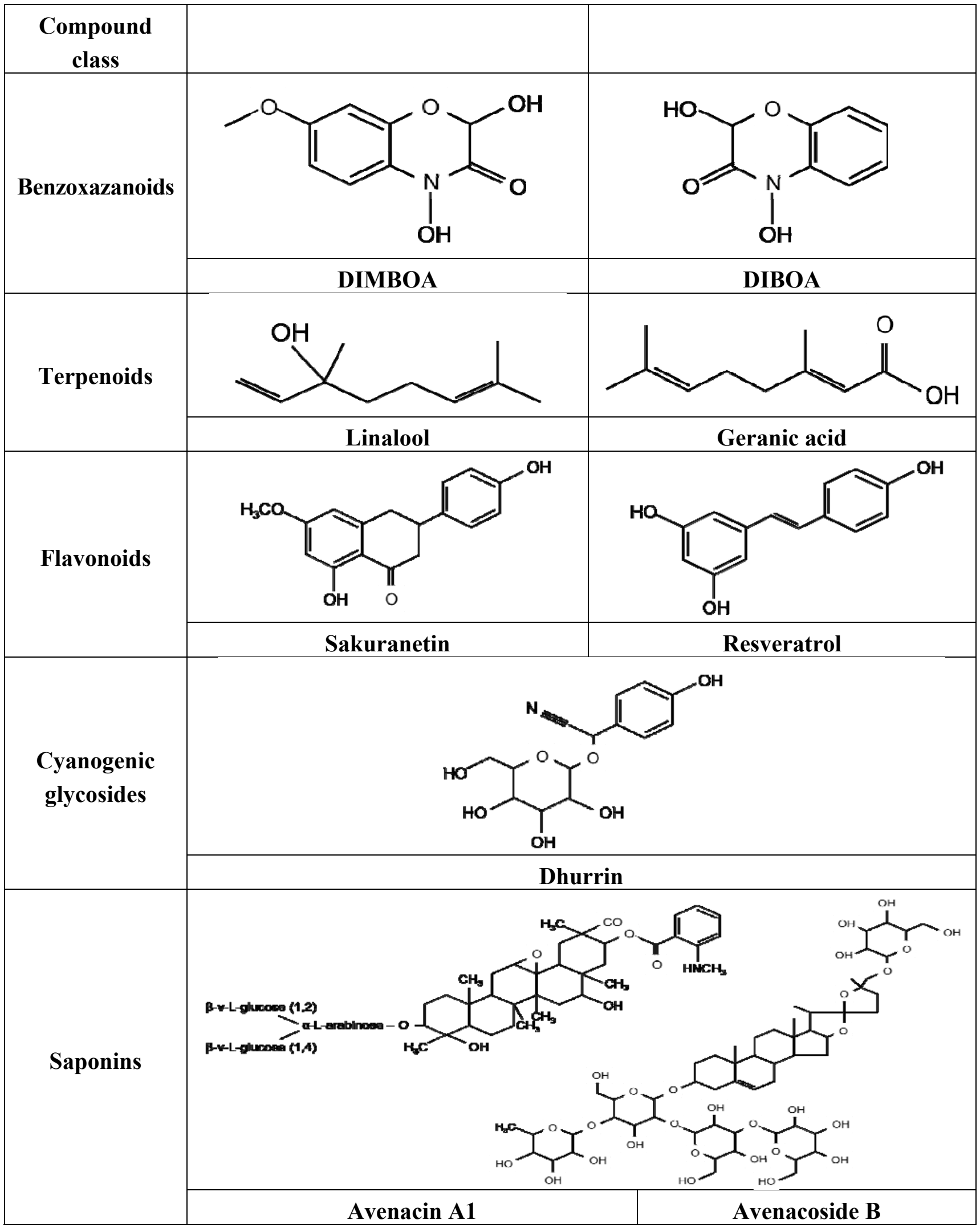


A recent study used LC-MS/MS to quantify Bxs in 54 Danish wheat varieties discovering the concentration of six Bxs to correlate positively with resistance to Fusarium Head Blight (FHB) [22]. FHB is a destructive disease affecting grain yield and cereal quality and is also capable of producing mycotoxins that can have significant effects on human health.

\section{Terpenes and Terpenoids}

The terpenes and terpenoids are the largest and most diverse class of secondary metabolites with over 40,000 compounds described [23]. Terpenes are synthesised from the basic five-carbon isoprene unit $\left(\mathrm{C}_{5} \mathrm{H}_{8}\right)$ by the mevalonate or non-mevalonate pathway (Figure 1). The isoprene units are added together via condensation reactions to form branched and cyclised isoprene polymers (hemiterpenes, monoterpenes, sesquiterpenes, diterpenes, sesterterpenes, triterpenes, tetraterpenes and polyterpenes). Terpenoids were originally defined as oxidised terpenes [24], however the term terpenoid is generally used to encompass both of these classes and will in this review. Terpenoids have an extensive range of important roles in the plant kingdom including functioning as plant hormones, electron carriers, vitamins, pigments and membrane components; a number are also involved in plant-pathogen interactions [25]. Terpenoids are produced in various cellular organelles often restricted to specific tissues where activity is required and they are stored in specialised secretory or glandular structures protecting the host plant from potential toxicity of the compounds $[25,26]$. The presence of a large number of terpenoid compounds in rice has been positively correlated with reduced pathogen infection [27]. Two diterpenoids produced in rice leaves upon Magnaporthe grisea infection, momilactones A and B have received particular attention for their antifungal activity against this fungus, the casual agent of the devastating rice blast disease [27-29]. Another group of similar diterpenoids named oryzalexin A-D were identified as rice phytoalexins also in M. grisea infected leaves [30-33]. Later, orzyalexin S and orzyalexin $\mathrm{E}$ and $\mathrm{F}$ were discovered as additional diterpenoids with potent antifungal activity [34-37]. Five cassane diterpenoids phytocassane A-E were found to increase upon M. grisea infection and present at higher concentrations in resistant strains in addition to having antifungal activity against another pathogenic fungus Rhizoctonia solani [38].

A recent study collected volatile organic compounds (VOCs) released by oat, barley and wheat in response to infection by three Fusarium species including two species that cause cortical rot disease of wheat. Piesik et al., measured the VOCs using GC-MS identifying two terpenes linalool (Figure 1) and $\beta$-caryophyllene to be present at higher concentrations in infected tissue than controls [39]. The same authors carried out a similar study in maize identifying three additional terpenes induced upon infection, $\beta$-pinene, $\beta$-myrcene and Z-ocimene [40]. A substantial amount of research into linalool synthesis and natural production has been undertaken due to its aroma and flavour in flower and vegetables for the application of perfume manufacture to metabolic engineering in tomatoes $[41,42]$. However, little is known regarding its involvement in plant pathogen interactions and the mechanism is assumed to be similar to other terpenoids for which evidence suggests interference and disruption of membranes [43-46]. Piesik et al. also demonstrated the ability of infected plants to lead to an increase in VOCs in uninfected neighbours. Control of VOC release in plants has significant potential for the management of crop pathogens. An early study of volatiles in wheat showed it contained the same major terpenoid species as oat and barley [47]. The utility of recent technological advances analysing 
VOCs using solid phase microextraction (SPME) and headspace techniques for the analysis of terpenes and other volatiles has been demonstrated [48].

Investigation into terpenoids with antifungal activity against two maize pathogens Fusarium graminearum and Colletotrichum graminicola identified geranic acid (Table 1), which had a minimal inhibitory concentration of $7.8 \mu \mathrm{g} / \mathrm{mL}$ and is the most potent antifungal towards these two pathogens discovered [49]. In an attempt at metabolic engineering to increase resistance of maize to these pathogens, the enzyme geraniol synthase was cloned and overexpressed. Non-targeted LC-MS metabolite profiling and volatile GC-MS headspace analysis identified significant differences in the volatile and non-volatile transgenic extracts of all geraniol derivatives. However, this did not translate into an increased resistance to $F$. graminearum or $C$. graminicola, the authors suggesting potential lack of bioavailability or inappropriate localisation that may be corrected by up or down-regulation of other genes involved in the pathway. Despite this, the author's are of the opinion that metabolic engineering of terpenoid metabolism in maize still has potential as the transgenic plants were of normal phenotype unlike previous attempts at terpenoid engineering in tomato, arabidopsis and potato [50-52].

\section{Flavonoids (Proanthocyanidins, Anthocyanins, Flavonols, Isolflavonoids)}

Flavonoids are a large class of phytoanticipan and phytoalexin phenolic metabolites synthesised from phenylalanine in the shikimate pathway (Figure 1) and includes the flavonols, flavones, flavanones, anthocyanidins, proanthocyanidins and chalcones. Flavonoids play an extensive role in many plant processes such as signalling; antioxidant activity, feeding deterrents, antimicrobial activity, UV protection, male fertility and flower pigmentation [53-55]. Flavonoids have received a significant amount of interest due to their potential uses in the pharmaceutical industry due to their anti-inflammatory and anticancer properties [56], however flavonoids also play numerous important roles in plant resistance, defence, signalling and symbiosis [57]. A number of mechanisms of antimicrobial action have been hypothesised for flavonoids including the crosslinking of microbial enzymes, inhibition of cellulases and other microbial enzymes, chelation of metals necessary for microbial enzyme activity and polymerisation into crystalline structures which may act as a physical barrier during pathogen attack [58].

A number of preformed flavonoids (phytoanticipans) belonging to the anthacyanidin class inhibit the growth and spore germination of the fungal and bacterial pathogens of rice M. grisea and Xanthomonas oryzae [59]. Flavonoid production can also be induced upon pathogen attack, an example of flavonoid phytoalexins are 3-deoxyanthocyanidin flavonoids induced in Sorghum by C. graminicola [60]. These secondary metabolites inhibit fungal growth in vitro and are induced during the initial stages of infection only in cells in direct contact with the fungus. The flavonoid sakuranetin (Figure 1) was identified using LC-MS to be induced following treatment of rice with the fungal elicitor chitosan [61]. Proanthocyanidins have been demonstrated to play a part in defence against Fusarium species through suggested mechanisms such as chelation of metals required for enzymatic activity, formation of a physical barrier, inhibition of cellulases and crosslinking of microbial enzymes [58]. A number of recent metabolomics studies employing an orbitrap LC-MS instrument have investigated barley resistance to Fusarium head blight identifying 16 flavonoids or isoflavonoids that were resistance related [62,63]; these compounds are yet to be tested for direct antifungal activity. LC-MS/MS analysis was used to identify two new flavonoid phytoalexins induced 
in response to inoculation of a resistant and susceptible cultivar of sorghum with Colletotrichum sublineolum [64]. Luteolin and apigenin were both present at higher concentrations in these cultivars suggestive of a phytoalexin role. Fungal germination bioassays indeed found luteolin to strongly inhibit fungal growth and spore germination; effects were similar but less dramatic for apigenin.

A number of flavonoid compounds require compartmentalisation in the cell to avoid mutagenic and oxidative effects of the active compounds and intermediates in their synthetic pathways. In maize, barley and rye a number of different mechanisms of vacuolar import have been identified including a vacuolar ATP-binding cassette $(\mathrm{ABC})$ transporter, multidrug resistance-associated protein like $\mathrm{ABC}$ transporter and $\mathrm{pH}$-dependent vacuolar flavonoid/H+ antiporters [65-68]. The synthesis of the flavone saponarin in mesophyll protoplasts without vacuoles was inhibited indicating that a functioning vacuole is critical for production of this flavone [69]. Flavonoids have recently been the subject of investigation into metabolic engineering of crop plants for the purposes of disease resistance to health benefits for humans [70]. Transgenic wheat and barley were constructed expressing a stilbene synthase gene from Vitis vinifera (Common Grape Vine) resulting in the production of the phytoalexin resveratrol (Figure 1) [71]. The authors present results detailing increased resistance of wheat and barley producing resveratrol to the necrotrophic pathogen Botrytis cinerea.

\section{Cyanogenic Glycosides}

Cyanogenic glycosides are present in over 2,600 plant species and a number of cereals including wheat, barley, oats, rye, sorghum, millets, sugar cane, maize and rice [72]. These compounds are derived from the amino acids valine, leucine, isoleucine, phenylalanine or tyrosine and the non-protein amino acid cyclopentenyl-glycine as path of the shikimate pathway (Figure 1) [73]. To avoid toxic release of hydrogen cyanide $(\mathrm{HCN})$ under normal conditions, cyanogenic glycosides are compartmentalised within cells separated from the HCN releasing $\beta$-glucosidases. Cyanogenic glycosides are activated by $\beta$-glucosidase-dependent hydrolysis to form the unstable aglycone upon tissue disruption. This cyanohydrin is further enzymatically (hydroxynitrile lyase) or spontaneously (at alkaline $\mathrm{pH}$ ) converted to a ketone or an aldehyde and the toxic constituent of the compound, HCN [74,75]. Cyanide is toxic to cells inhibiting the oxidative function of mitochondria cytochrome oxidase thereby reducing the cells ability to use oxygen for aerobic respiration [76,77]. The cyanogenic glycoside dhurrin (Figure 1) found in Sorghum is only located in the epidermal layers of the leaf while the $\beta$-glucosidases and $\alpha$-hydroxynitrile lyase enzymes capable of activation and release of HCN were located only in mesophyll tissue [78].

There is evidence that the production of cyanogenic glycosides occurs at a significant cost to the plant suggesting they must play a role in survival against herbivores or pathogens [79]. Some fungi are capable of detoxifying HCN [80] while others are capable of cyanide-resistant respiration [81]. While there is indisputable evidence for a role of cyanogenic glycosides as herbivore deterrents [72,82], there is little reliable evidence for direct roles against pathogens [17,83]. Very early studies have related the Fusarium wilt resistance of flax to $\mathrm{HCN}$ release in roots [84]. HCN release occurs in leaves of Lotus corniculatus upon pathogen invasion arresting the development of most fungal species [84]. A recent study in barley investigated five leucine-derived cyano glycosides however discovered that the 
$\beta$-glucosidase that hydrolyses them is only present in the endosperm of germinating barley therefore concluding that the cyanide potential of barley cannot be harnessed in a fungal attack [73].

High performance liquid chromatography (HPLC) and LC-MS/MS for the analysis and identification of cyanogenic glycosides has recently been exploited for the sensitive detection of these compounds and their derivatives [85-87]. The potential of these techniques should be utilised to confirm the role of these compounds in plant defence.

\section{Saponins}

Saponins are a class of glycosylated triterpenes; steroids and steroidal alkaloids synthesised from the mevalonate or non-mevalonate pathway in plants (Figure 1) and are absent in the majority of monocotyledon plants and all cereals with the exception of oat (Avena). These phytoanticipans possess a broad range of biological activities including antimicrobial, insecticidal, allelopathic action and molluscidal acitivity $[17,88]$. Oat contains two types of Saponins-Four triterpenoid avenacins and two steroidal avenacosides (Figure 1) present in roots and leaves respectively [89,90]. Avenacins are active in their natural glycoslyated form in the plant in contrast to avenacosides, benzoxazanoids and many other antifungal compounds which are active only in their aglycone forms [91,92]. The inactive avenacosides are stored in the vacuole of the plant and activated when tissue damage caused by pathogenic fungi disrupts membranes allowing the plant enzyme $\beta$-glucosidase to hydrolyse the D-glucose unit forming the biologically active aglycone [93]. The active form of the avenacosides then forms complexes with membrane sterols disrupting the fungi's plasma membrane by pore formation resulting in fungal cell death. Avenacins, which are active in their native form, are also stored in the vacuole of plants, which are protected from their toxic effects by a different membrane sterol composition $[17,89,94]$. In line with this, several fungi are resistant to saponin-producing plants due to their natural membrane composition. The biological activity and biosynthesis of saponins has been recently reviewed [95].

Saponins have been implicated in the resistance of oat to Gaeumannomyces graminis var. tritici referred to as the 'take all' disease causing severe crop losses in saponin deficient barley and wheat [96]. This hypothesised saponin-conferred resistance of oat is supported by the ability of G. graminis var. avenae to infect oat due to the possession of the saponin-detoxifying enzyme avenacinase [97]. Saponins are induced by elicitors of defence responses such as jasmonate derivatives [98] again emphasising their role in defence.

In the past, research on saponins has proved difficult, relying on HPLC methods or non-specific stains [88] however recent developments in mass spectrometry and metabolite profiling are enabling the high throughput screening and identification of a large number of these secondary metabolites. These techniques are now being employed to ascertain biosynthetic mechanisms of saponins and related compounds in different plant species and have potential to identify new metabolites belonging to this class of compounds [99]. GC-MS has been combined with gene expression analysis to identify a number of genes involved in triterpene synthesis to also be present in rice. Expression of the oxidosqualene cyclase (OSC) enzyme AsbAB1 encoding the $\beta$-amyrin synthase in rice showed that rice is capable of $\beta$-amyrin synthesis [100] hence identifying the potential for metabolic engineering of 
saponin regulated resistance in other cereals. A method for the quantification of saponins using LC-MS/MS has recently been developed [101].

\section{Conclusion}

This review has covered the major classes of secondary metabolites present in cereals with important roles in pathogen defence. The majority of these plant secondary metabolites, whether preformed or induced, are compartmentalised within vacuoles or other specialised cellular compartments to avoid self-toxicity. A common mechanism of activation is enzymatic hydrolysis following vacuole disruption during tissue damage caused by the pathogen. Other compounds accumulate in the apoplast such as benzoxazanoids, which act as defence regulatory signals. Volatile secondary metabolites are also involved in pathogen defence with a number of volatile terpenoids demonstrated to increase in response to pathogen attack. Infected plants are also capable of stimulating volatile release from uninfected neighbouring plants, a feature that may be invaluable to increasing crop resistance to pathogens. The mechanism of action of the antimicrobial secondary metabolites discussed in this review varies from membrane disruption and pore formation (saponins and terpenoids) to interference with aerobic respiration (cyanogenic glycosides) and inhibition of microbial enzymes, chelation of metals required for microbial enzymes and polymerisation forming crystalline physical defence barriers (flavonoids). Microbes are constantly evolving mechanisms to overcome the activity of such compounds as are plants evolving new defence mechanisms. If the potential of metabolite engineering is harnessed, cereals may not be limited to only the classes of secondary defence compounds discussed in this review.

The discovery of secondary metabolites with roles in pathogen defence has been catalysed in recent years with technical advances in mass spectrometry and high throughput metabolite profiling. Many of the metabolites described in this review have been identified via gas chromatography and headspace analysis of volatiles coupled to mass spectrometers in addition to liquid chromatography-mass spectrometry and occasionally nuclear magnetic resonance spectroscopy. The current bottleneck in these techniques is the processing of the large data sets generated and positive identification of all the compounds analysed.

\section{References}

1. Saari, E.E.; Prescott, J.M. World distribution in relation to economic losses. In The Cereal Rusts; Roelfs, A.P., Bushnell, W.R., Eds.; Academic Press: Orlando, Florida, FL, USA, 1985; Volume 2, pp. 259-298.

2. Food and Agriculture Organisation of the United Nations. Available online: http://faostat.fao.org/ (accessed on 30 November 2011).

3. Zeigler, R.S.; Leong, S.A.; Teng, P.S. Rice Blast Disease; CABI publishing: Wallingford, UK, 1994.

4. Parry, D.W.; Jenkinson, P.; McLeod, L. Fusarium ear blight (scab) in small grain cerealsA review. Plant Pathol. 1995, 44, 207-238. 
5. Sudha, G.; Ravishankar, G.A. Involvement and interaction of various signaling compounds on the plant metabolic events during defense response, resistance to stress factors, formation of secondary metabolites and their molecular aspects. Plant Cell Tissue Organ Cult. 2002, 71, 181-212.

6. Dangl, J.L.; Jones, J.D.G. Plant pathogens and integrated defence responses to infection. Nature 2001, 411, 826-833.

7. Bennett, R.N.; Wallsgrove, R.M. Transley Review No.72. Secondary metabolites in plant defence mechanisms. New Phytol. 1994, 127, 617-633.

8. Iriti, M.; Faoro, F. Chemical diversity and defence metabolism: How plants cope with pathogens and ozone pollution. Int. J. Mol. Sci. 2009, 10, 3371-3399.

9. Müller, K.O.; Borger, H. Experimentelle Untersuchungen über die PhytophthorainfestansResistenz der Kartoffel. Arb. Biol. Reichsanst. Land Forstwirtsch 1940, 23, 189-131.

10. VanEtten, H.D.; Mansfield, J.W.; Bailey, J.A.; Farmer, E.E. Two classes of plant antibiotics: Phytoalexins versus "Phytoanticipins". Plant Cell 1994, 6, 1191-1192.

11. Wink, M. Plant breeding: Importance of plant secondary metabolites for protection against pathogens and herbivores. Theor. Appl. Genet. 1988, 75, 225-233.

12. Robbins, M.P.; Morris, P. Metabolic engineering of condensed tannins and other phenolic pathways in forage and fodder crops. In Metabolic Engineering of Plant Secondary Metabolism; Verpoorte, R.; Alfermann, A.W., Eds.; Springer-Verlag: Heidelberg, Germany, 2000; pp. 165-179.

13. Virtanen, A.I.; Hietala, P.K. 2(3)-Benzoxazolinone, an anti-Fusarium factor in rye seedlings. Acta Chem. Scand. 1955, 9, 1543-1544.

14. Bravo, H.R.; Lazo, W. Antialgal and antifungal activity of natural hydroxamic acids and related compounds. J. Agric. Food Chem. 1996, 44, 1569-1571.

15. Niemeyer, H.M. Hydroxamic acids (4-hydroxy-1,4-benzoxazin-3-ones), defence chemicals in the gramineae. Phytochemistry 1988, 27, 3349-3358.

16. Sicker, D.; Frey, M.; Schulz, M.; Gierl, A. Role of natural benzoxazinones in the survival strategy of plants. Int. Rev. Cytol. 2000; 198, 319-346.

17. Osbourn, A.E. Preformed antimicrobial compounds and plant defense against fungal attack. Plant Cell 1996, 8, 1821-1831.

18. Hashimoto, Y.; Shudo, K. Chemistry of biologically active benzoxazinoids. Phytochemistry 1996, 43, 551-559.

19. Niemeyer, H.M. Hydroxamic acids derived from 2-hydroxy-2H-1,4-benzoxazin-3(4H)-one: Key defense chemicals of cereals. J. Agric. Food Chem. 2009, 57, 1677-1695.

20. Ahmad, S.; Veyrat, N.; Gordon-Weeks, R.; Zhang, Y.; Martin, J.; Smart, L.; Glauser, G.; Erb, M.; Flors, V.; Frey, M.; et al. Benzoxazinoid metabolites regulate innate immunity against aphids and fungi in maize. Plant Physiol. 2011, 157, 317 - 327.

21. Hanhineva, K.; Rogachev, I.; Aura, A.M.; Aharoni, A.; Poutanen, K.; Mykknen, H. Qualitative characterization of benzoxazinoid derivatives in whole grain rye and wheat by LC-MS metabolite profiling. J. Agric. Food Chem. 2011, 59, 921-927.

22. Søltoft, M.; Jørgensen, L.N.; Svensmark, B.; Fomsgaard, I.S. Benzoxazinoid concentrations show correlation with Fusarium Head Blight resistance in Danish wheat varieties. Biochem. Syst. Ecol. 2008, 36, 245-259. 
23. Morrone, D.; Hillwig, M.L.; Mead, M.E.; Lowry, L.; Fulton, D.B.; Peters, R.J. Evident and latent plasticity across the rice diterpene synthase family with potential implications for the evolution of diterpenoid metabolism in the cereals. Biochem. J. 2011, 435, 589-595.

24. Cowan, M.M. Plant products as antimicrobial agents. Clin. Microbiol. Rev. 1999, 12, 564-582.

25. McGarvey, D.J.; Croteau, R. Terpenoid metabolism. Plant Cell 1995, 7, 1015-1026.

26. Langenheim, J.H. Higher plant terpenoids: A phytocentric overview of their ecological roles. J. Chem. Ecol. 1994, 20, 1223-1280.

27. Peters, R.J. Uncovering the complex metabolic network underlying diterpenoid phytoalexin biosynthesis in rice and other cereal crop plants. Phytochemistry 2006, 67, 2307-2317.

28. Cartwright, D.; Langcake, P.; Pryce, R.J.; Leworthy, D.P.; Ride, J.P. Chemical activation of host defence mechanisms as a basis for crop protection. Nature 1977, 267, 511-513.

29. Cartwright, D.W.; Langcake, P.; Pryce, R.J.; Leworthy, D.P.; Ride, J.P. Isolation and characterization of two phytoalexins from rice as momilactones A and B. Phytochemistry 1981, 20, 535-537.

30. Akatsuka, T.; Kodama, O.; Kato, H.; Kono, Y.; Takeuchi, S. 3-Hydroxy-7-oxo-sandaracopimaradiene (Oryzalexin A), a new phytoalexin isolated from rice blast leaves. Agric. Biol. Chem. 1983, 47, 445-447.

31. Kono, Y.; Takeuchi, S.; Kodama, O.; Akatsuka, T.N. Absolute configuration of oryzalexin A and structures of its related phytoalexins isolated from rice blast leaves infected with Pyricularia oryzae. Agric. Biol. Chem. 1984, 48, 253-255.

32. Kono, Y.; Takeuchi, S.; Kodama, O.; Sekido, H.; Akatsuka, T.N. Novel phytoalexins (Oryzalexins A, B and C) isolated from rice blast leaves infected with Pyricularia oryzae. Part II: Structural studies of oryzalexins. Agric. Biol. Chem. 1985, 49, 1695-1701.

33. Sekido, H.; Endo, T.; Suga, R.; Kodama, O.; Akatsuka, T.; Kono, Y.; Takeuchi, S. Oryzalexin D (3,7-dihydroxy-(+)-sandaracopimaradiene), a new phytoalexin isolated from blast-infected rice leaves. J. Pestic. Sci. 1986, 11, 369-372.

34. Kato, H.; Kodama, O.; Akatsuka, T.N. Oryzalexin E, a diterpene phytoalexin from UV-irradiated rice leaves. Phytochemistry 1993, 33, 79-81.

35. Kato, H.; Kodama, O.; Akatsuka, T. Oryzalexin F, a diterpene phytoalexin from UV-irradiated rice leaves. Phytochemistry 1994, 36, 299-301.

36. Kodama, O.; Li, W.X.; Tamogami, S.; Akatsuka, T.N. Oryzalexin S, a novel stermarane-type diterpene rice phytoalexin. Biosci. Biotechnol. Biochem. 1992, 56, 1002-1003.

37. Kodama, O.; Suzuki, T.; Miyakawa, J.; Akatsuka, T. Ultraviolet-induced accumulation of phytoalexins in rice leaves. Agric. Biol. Chem. 1988, 52, 2469-2473.

38. Koga, J.; Ogawa, N.; Yamauchi, T.; Kikuchi, M.; Ogasawara, N.; Shimura, M. Functional moiety for the antifungal activity of phytocassane E, a diterpene phytoalexin from rice. Phytochemistry 1997, 44, 249-253.

39. Piesik, D.; Pańka, D.; Delaney, K.J.; Skoczek, A.; Lamparski, R.; Weaver, D.K. Cereal crop volatile organic compound induction after mechanical injury, beetle herbivory (Oulema spp.), or fungal infection (Fusarium spp.). J. Plant Physiol. 2011, 168, 878-886. 
40. Piesik, D.; Lemńczyk, G.; Skoczek, A.; Lamparski, R.; Bocianowski, J.; Kotwica, K.; Delaney, K.J. Fusarium infection in maize: Volatile induction of infected and neighboring uninfected plants has the potential to attract a pest cereal leaf beetle, Oulema melanopus. J. Plant Physiol. 2011, $168,1534-1542$.

41. Lewinsohn, E.; Schalechet, F.; Wilkinson, J.; Matsui, K.; Tadmor, Y.; Nam, K.-H.; Amar, O.; Lastochkin, E.; Larkov, O.; Ravid, U.; et al. Enhanced levels of the aroma and flavor compound S-linalool by metabolic engineering of the terpenoid pathway in tomato fruits. Plant Physiol. 2001, 127, 1256-1265.

42. Raguso, R.A.; Pichersky, E. New perspectives in pollination biology: Floral fragrances. A day in the life of a linalool molecule: Chemical communication in a plant-pollinator system. Part 1: Linalool biosynthesis in flowering plants. Plant Spec. Biol. 1999, 14, 95-120.

43. Abramov, A.Y.; Zamaraeva, M.V.; Hagelgans, A.I.; Azimov, R.R.; Krasilnikov, O.V. Influence of plant terpenoids on the permeability of mitochondria and lipid bilayers. BBA-Biomembranes 2001, 1512, 98-110.

44. Zore, G.B.; Thakre, A.D.; Jadhav, S.; Karuppayil, S.M. Terpenoids inhibit Candida albicans growth by affecting membrane integrity and arrest of cell cycle. Phytomedicine 2011, 18, 1181-1190.

45. Trombetta, D.; Castelli, F.; Sarpietro, M.G.; Venuti, V.; Cristani, M.; Daniele, C.; Saija, A.; Mazzanti, G.; Bisignano, G. Mechanisms of antibacterial action of three monoterpenes. Antimicrob. Agents Chemother. 2005, 49, 2474-2478.

46. Khandelia, H.; Witzke, S.; Mouritsen, O.G. Interaction of salicylate and a terpenoid plant extract with model membranes: Reconciling experiments and simulations. Biophys. J. 2010, 99, 3887-3894.

47. Buttery, R.G.; Xu, C.; Ling, L.C. Volatile components of wheat leaves (and stems): Possible insect attractants. J. Agric. Food Chem. 1985, 33, 115-117.

48. Beleggia, R.; Platani, C.; Spano, G.; Monteleone, M.; Cattivelli, L. Metabolic profiling and analysis of volatile composition of durum wheat semolina and pasta. J. Cereal Sci. 2009, 49, 301-309.

49. Yang, T.; Stoopen, G.; Yalpani, N.; Vervoort, J.; de Vos, R.; Voster, A.; Verstappen, F.W.A.; Bouwmeester, H.J.; Jongsma, M.A. Metabolic engineering of geranic acid in maize to achieve fungal resistance is compromised by novel glycosylation patterns. Metab. Eng. 2011, 13, 414-425.

50. Aharoni, A.; Giri, A.P.; Deuerlein, S.; Griepink, F.; De Kogel, W.J.; Verstappen, F.W.A.; Verhoeven, H.A.; Jongsma, M.A.; Schwab, W.; Bouwmeester, H.J. Terpenoid metabolism in wild-type and transgenic arabidopsis plants. Plant Cell 2003, 15, 2866-2884.

51. Aharoni, A.; Jongsma, M.A.; Kim, T.Y.; Ri, M.B.; Giri, A.P.; Verstappen, F.W.A.; Schwab, W.; Bouwmeester, H.J. Metabolic engineering of terpenoid biosynthesis in plants. Phytochem. Rev. 2006, 5, 49-58.

52. Davidovich-Rikanati, R.; Lewinsohn, E.; Bar, E.; Iijima, Y.; Pichersky, E.; Sitrit, Y. Overexpression of the lemon basil $\alpha$-zingiberene synthase gene increases both mono- and sesquiterpene contents in tomato fruit. Plant J. 2008, 56, 228-238.

53. Shirley, B.W. Flavonoids in seeds and grains: Physiological function, agronomic importance and the genetics of biosynthesis. Seed Sci. Res. 1998, 8, 415-422.

54. Treutter, D. Significance of flavonoids in plant resistance and enhancement of their biosynthesis. Plant Biol. 2005, 7, 581-591. 
55. Sirikantaramas, S.; Yamazaki, M.; Saito, K. Mechanisms of resistance to self-produced toxic secondary metabolites in plants. Phytochem. Rev. 2008, 7, 467-477.

56. García-Lafuente, A.; Guillamón, E.; Villares, A.; Rostagno, M.A.; Martínez, J.A. Flavonoids as anti-inflammatory agents: Implications in cancer and cardiovascular disease. Inflamm. Res. 2009, 58, 537-552.

57. Treutter, D. Significance of flavonoids in plant resistance: A review. Environ. Chem. Lett. 2006, $4,147-157$

58. Skadhauge, B.; Thomsen, K.K.; Von Wettstein, D. The role of the barley testa layer and its Flavonoid content in resistance to fusarium infections. Hereditas 1997, 126, 147-160.

59. Padmavati, M.; Sakthivel, N.; Thara, K.V.; Reddy, A.R. Differential sensitivity of rice pathogens to growth inhibition by flavonoids. Phytochemistry 1997, 46, 499-502.

60. Snyder, B.A.; Nicholson, R.L. Synthesis of phytoalexins in sorghum as a site-specific response to fungal ingress. Science 1990, 248, 1637-1639.

61. Agrawal, G.K.; Rakwal, R.; Tamogami, S.; Yonekura, M.; Kubo, A.; Saji, H. Chitosan activates defense/stress response(s) in the leaves of Oryza sativa seedlings. Plant Phys. Biochem. 2002, 40, 1061-1069.

62. Bollina, V.; Kumaraswamy, G.; Kushalappa, A.C.; Choo, T.; Dion, Y.; Rioux, S.; Faubert, D.; Hamzehzarghani, H. Mass spectrometry-based metabolomics application to identify quantitative resistance-related metabolites in barley against Fusarium head blight. Mol. Plant Pathol. 2010, 11, 769-782.

63. Kumaraswamy, G.K.; Bollina, V.; Kushalappa, A.C.; Choo, T.M.; Dion, Y.; Rioux, S.; Mamer, O.; Faubert, D. Metabolomics technology to phenotype resistance in barley against Gibberella zeae. Eur. J. Plant Pathol. 2011, 130, 29-43.

64. Du, Y.; Chu, H.; Wang, M.; Chu, I.K.; Lo, C. Identification of flavone phytoalexins and a pathogen-inducible flavone synthase II gene (SbFNSII) in sorghum. J. Exp. Bot. 2010, 61, 983-994.

65. Goodman, C.D.; Casati, P.; Walbot, V. A multidrug resistance-associated protein involved in anthocyanin transport in Zea mays. Plant Cell 2004, 16, 1812-1826.

66. Marinova, K.; Pourcel, L.; Weder, B.; Schwarz, M.; Barron, D.; Routaboul, J.M.; Debeaujon, I.; Kleina, M. The Arabidopsis MATE transporter TT12 acts as a vacuolar flavonoid/H +-antiporter active in proanthocyanidin-accumulating cells of the seed coat. Plant Cell 2007, 19, 2023-2038.

67. Klein, M.; Martinoia, E.; Hoffmann-Thoma, G.; Weissenbck, G. A membrane-potential dependent ABC-like transporter mediates the vacuolar uptake of rye flavone glucuronides: Regulation of glucuronide uptake by glutathione and its conjugates. Plant J. 2000, 21, 289-304.

68. Klein, M.; Weissenbck, G.; Dufaud, A.; Gaillard, C.; Kreuz, K.; Martinoia, E. Different energization mechanisms drive the vacuolar uptake of a flavonoid glucoside and a herbicide glucoside. J. Biol. Chem. 1996, 271, 29666-29671.

69. Marinova, K.; Kleinschmidt, K.; Weissenbck, G.; Klein, M. Flavonoid biosynthesis in barley primary leaves requires the presence of the vacuole and controls the activity of vacuolar flavonoid transport. Plant Physiol. 2007, 144, 432-444.

70. Schijlen, E.G.W.M.; Ric de Vos, C.H.; van Tunen, A.J.; Bovy, A.G. Modification of flavonoid biosynthesis in crop plants. Phytochemistry 2004, 65, 2631-2648. 
71. Leckband, G.; Lörz, H. Transformation and expression of a stilbene synthase gene of Vitis vinifera L. in barley and wheat for increased fungal resistance. TAG Theor. Appl. Genet. 1998, 96, 1004-1012.

72. Jones, D.A. Why are so many food plants cyanogenic? Phytochemistry 1998, 47, 155-162.

73. Nielsen, K.A.; Olsen, C.E.; Pontoppidan, K.; Møller, B.L. Leucine-derived cyano glucosides in barley. Plant Physiol. 2002, 129, 1066-1075.

74. Conn, E.E. Cyanogenic compounds. Ann. Rev. Plant Phys. 1980, 31, 433-451.

75. Poulton, J.E. Cyanogenesis in plants. Plant Physiol. 1990, 94, 401-405.

76. Castric, P.A. Hydrogen cyanide production by Pseudomonas aeruginosa at reduced oxygen levels. Can. J. Microbiol. 1983, 29, 1344-1349.

77. Nelson, L. Acute cyanide toxicity: Mechanisms and manifestations. J. Emerg. Nurs. 2006, 32 (Suppl. 4), S8-S11.

78. Kojima, M.; Poulton, J.E.; Thayer, S.S.; Conn, E. Tissue distributions of dhurrin and of enzymes involved in its metabolism in leaves of sorghum bicolor. Plant Physiol. 1979, 63, 1022-1028.

79. Kakes, P. An analysis of the costs and benefits of the cyanogenic system in Trifolium repens. TAG Theor. Appl.Genet. 1989, 77, 111-118.

80. Wang, P.; Matthews, D.E.; VanEtten, H.D. Purification and characterization of cyanide hydratase from the phytopathogenic fungus Gloeocercospora sorghi. Arch. Biochem. Biophys. 1992, 298, 569-575.

81. Lieberei, R. Relationship of cyanogenic capacity $(\mathrm{HCN}-\mathrm{c})$ of the rubber tree hevea brasiliensis to susceptibility to microcyclus ulei, the agent causing South American Leaf Blight. J. Phytopathol. 1988, 122, 54-67.

82. Tattersall, D.B.; Bak, S.; Jones, P.R.; Olsen, C.E.; Nielsen, J.K.; Hansen, M.L.; Høj, P.B.; Møller, B.L. Resistance to an herbivore through engineered cyanogenic glucoside synthesis. Science 2001, 293, 1826-1828.

83. Fry, W.E.; Millar, R.L. Cyanide degradion by an enzyme from Stemphylium loti. Arch. Biochem. Biophys. 1972, 151, 468-474.

84. Levin, D.A. The chemical defenses of plants to pathogens and herbivores. Annu. Rev. Ecol. Syst. 1976, 7, 121-159.

85. Tan, H.P.; Ling, S.K.; Chuah, C.H. Characterisation of galloylated cyanogenic glucosides and hydrolysable tannins from leaves of phyllagathis rotundifolia by LC-ESI-MS/MS. Phytochem. Anal. 2011, 22, 516-525.

86. De Nicola, G.R.; Leoni, O.; Malaguti, L.; Bernardi, R.; Lazzeri, L. A simple analytical method for dhurrin content evaluation in cyanogenic plants for their utilization in fodder and biofumigation. J. Agric. Food Chem. 2011, 59, 8065-8069.

87. Johansen, H.; Rasmussen, L.H.; Olsen, C.E.; Bruun Hansen, H.C. Rate of hydrolysis and degradation of the cyanogenic glycoside-dhurrin-in soil. Chemosphere 2007, 67, 259-266.

88. Hostettmann, K.A.; Marston, A. Saponins; Cambridge University Press: Cambridge, UK, 1995.

89. Price, K.R.; Johnson, I.T.; Fenwick, G.R. The chemistry and biological significance of saponins in foods and feedingstuffs. Critic. Rev. Food Sci. Nutr. 1987, 26, 27-135.

90. Goodwin, R.H.; Pollock, B.M. Studies on Roots. I. Properties and distribution of fluorescent constituents in avena roots. Am. J. Bot. 1954, 41, 516-520. 
91. Crombie, L.; Crombie, W.M.L.; Whiting, D.A. Structures of the four avenacins, oat root resistance factors to 'take-all' disease. J. Chem. Soci. Chem. Commun. 1984, 4, 246-248.

92. Ingham, J.L. Disease resistance in higher plants the concept of pre-infectional and post-infectional resistance. J. Phytopathol. 1973, 78, 314-335.

93. Nisius, A. The stromacentre inAvena plastids: An aggregation of $\beta$-glucosidase responsible for the activation of oat-leaf saponins. Planta 1988, 173, 474-481.

94. Mylona, P.; Owatworakit, A.; Papadopoulou, K.; Jenner, H.; Qin, B.; Findlay, K.; Hill, L.; Qi, X.; Bakht, S.; Melton, R.; et al. Sad3 and Sad4 are required for saponin biosynthesis and root development in oat. Plant Cell 2008, 20, 201-212.

95. Augustin, J.M.; Kuzina, V.; Andersen, S.B.; Bak, S. Molecular activities, biosynthesis and evolution of triterpenoid saponins. Phytochemistry 2011, 72, 435-457.

96. Turner, E.M. The nature of the resistance of oats to the take-all fungus. J. Exp. Bot. 1956, 7, 80-92.

97. Bowyer, P.; Clarke, B.R.; Lunness, P.; Daniels, M.J.; Osbourn, A.E. Host range of a plant pathogenic fungus determined by a saponin detoxifying enzyme. Science 1995, 267, 371-374.

98. Yendo, A.; de Costa, F.; Gosmann, G.; Fett-Neto, A. Production of plant bioactive triterpenoid saponins: Elicitation strategies and target genes to improve yields. Mol. Biotechnol. 2010, 46, 94-104.

99. Qin, B.; Eagles, J.; Mellon, F.A.; Mylona, P.; Peña-Rodriguez, L.; Osbourn, A.E. High throughput screening of mutants of oat that are defective in triterpene synthesis. Phytochemistry 2010, 71, 1245-1252.

100. Inagaki, Y.-S.; Etherington, G.; Geisler, K.; Field, B.; Dokarry, M.; Ikeda, K.; Mutsukado, Y.; Dicks, J.; Osbourn, A. Investigation of the potential for triterpene synthesis in rice through genome mining and metabolic engineering. New Phytol. 2011, 191, 432-448.

101. Munafo, J.P.; Gianfagna, T.J. Quantitative analysis of steroidal glycosides in different organs of Easter Lily (Lilium longiflorum Thunb.) by LC-MS/MS. J. Agric. Food Chem. 2011, 59, 995-1004.

(C) 2011 by the authors; licensee MDPI, Basel, Switzerland. This article is an open access article distributed under the terms and conditions of the Creative Commons Attribution license (http://creativecommons.org/licenses/by/3.0/). 